\title{
Best Practices in Training of Employees: A Framework for Training the Personnel of Social Partners and NGOs
}

Nikos Papadakis*, Argyris Kyridis ${ }^{1 *}$, Prokopis Pandis $^{2} *$ \& Christos Zagkos ${ }^{3 *}$

*Assistant Professor, Dept. of Political Science, University of Crete

University Campus, Rethymnon,74100, Greece

E-mail:nep@pol.soc.uoc.gr

${ }^{1}$ *Professor, Dept. of preschool education, Faculty of Education

Aristotle University of Thessaloniki, Thessaloniki, Greece

E-mail: akiridis@nured.auth.gr

2*Ph.D., Researcher, Centre for Educational Policy Development (KANEP/GSEE)

3rd Septemvriou 36, Athens 10432, Greece

E-mail:ppandis@yahoo.com

${ }^{3}$ *Correspondence: Ph.D., Researcher, Centre for Educational Policy Development (KANEP/GSEE), 3rd Septemvriou 36, Athens 10432, Greece

E-mail:zagbal2003@yahoo.gr

Received: December 28, 2011 Accepted: March 25, 2012 Published: June 10, 2012

doi:10.5296/ije.v4i2.1201ＵRL: http://dx.doi.org/10.5296/ije.v4i2.1201 


\begin{abstract}
In the modern, knowledge-driven economy, it has been argued that people must upgrade their skills in order to remain competitive and to prepare for frequent changes in jobs. Adult learning is seen extremely crucial for long-term employability. Availability of adequately trained human resources in any institution is most critical to its success; and education and training play a significant role in this connection. This paper seeks the best practices for training of personnel. Initially, a detailed review of the international experience in this matter is presented and then the authors introduce a framework of a comprehensive program of personnel training in social partners and NGOs.
\end{abstract}

Keywords: adult education, best practices, training of employees, lifelong learning 


\section{Adult education and the need for a new proposal in the training of social partners' and NGOs' personnel in Greece}

Education and training are seen as key factors in the process of making companies and nations more competitive and increasing the employability of the workforce. The Lisbon Strategy (2000) formulated a vision of the EU as a competitive knowledge-based economy, and social partners are recognised as important players at all levels (enterprise, sector, national and cross-national) in this endeavour. Since 2002, they have been recognised through a joint strategy entitled 'Framework of actions for the lifelong development of competencies and qualifications' and have played an important role in the implementation of the Lisbon Strategy by contributing to the formulation of guidelines on how to ensure growth, generate employment and enhance competitiveness (Mayen, 2011).

In E.U. member countries during the last decades both the social partners (employers and trade unions) and voluntary bodies appear to be increasingly recognizing that adult education and training are part of their remit and therefore they have become providers of adult education. Investment in adult learning increases the adaptability of the workforce, the ability of employees to engage in dialogue and the effectiveness of volunteers in community settings. However, in Greece the training of employees is still in a primary phase. Effect of this fact is the deficiency of well trained personnel and the complete lack of structures for the training of employees. These shortcomings lead respectively to bad services, administrative inefficiencies, waste of resources and corruption. Only during the last few years the two major trade unions of Greece G.S.E.E. (General Confederation of Greek Workers) and A.D.E.D.Y.(Civil Servants' Confederation) have made some serious efforts to present a well organized project of adult education.

This piece of research has a dual objective: on the one hand to record how the training programmes in Europe are structured based on best practices and on the other hand to suggest an analytical training program for the employees of social partners and NGOs aiming at the integration of this program from the training structures in order to improve their educational services.

\section{Structure and theoretical foundation for the detection criteria of best practices}

Best practice can be generally defined as the appropriate handling of a concentrated knowledge in any field of human experience which results in practice (Clarke \& Foweraker, 2001). Two different approaches dominate the discussion for best practices. One is the World Bank's approach for good governance (Kieley, 1998). The second example involves the wider context of sustainable development (Roy \& Tisdell, 1998). Both approaches, however, are directly linked to the broader issues of democracy and governance. The term "best practices" is used in many fields. The term regards basically founded and substantiated evidence-based instructions, techniques or methodologies that their implementation has proven to drive safely and reliably to a desired outcome in a given context. The adoption of best practices ensures the widespread use of the results, while minimizes the utility costs. According to the United Nations (2004), best practices are defined as the operating practices that have proven 
successful in certain situations; those practices are used in order to show what works and what does not and to accumulate knowledge about how and why they work in different contexts and situations.

The two key elements for the assessment of best practices is their proof of success and their transferability (Advance Africa, 2003). According to UNESCO, best practices have four common characteristics:

- are innovative: a best practice develop new and creative solutions to common problems

- make a difference: a best practice has a positive and tangible impact on groups or individuals,

- have a permanent effect: best practices drastically affect the subjects which they concern

- are easily copied and implemented: best practices are acting as models, creating policies and innovations in various places.

The World Bank has identified a number of criteria on which must be built a best practice for training and education should be built. These criteria are:

$>$ Legality

$>$ Relevance

$>$ Measurable Results

$>$ Cooperation between partners

$>$ Durability

$>$ Innovation and learning

$>$ Upgradeability.

In fact, a practice in order to ensure its legitimacy, must have received recognition from reliable sources such as academic schools, groups of specialists, specialized agencies, international organizations or other relevant entities. Also, the World Bank states that important role in a successful practice plays the cooperation and the coordination between partners, public and private. The decision-making should be based on knowledge exchange, dialogue and negotiation between all stakeholders. In parallel, a practice characterized as "best" when its results and its impact last on time. In order to do so the specific process should be monitored and evaluated. Finally, a practice could be considered "best" when it can be transferred to other structures and environments either alone or with some modifications and extensions.

However, the above criteria are not on their own sufficient to create a "best" practice in the multifaceted field of "in service" training, even if they reliably irrigated by the international experience and the suzerain transnational trends. Education, training and personnel training is a process that requires even more specialized criteria to identify a "best" practice. We must not overlook that when we talk about training personnel we automatically 
talk about adult education. So the characteristics of the target group should be the foundation of our approach. In each case in the current international environment, there are a number of criteria that should be examined in order to build a "best" practice for training and retraining staff and trade unionists of social partners or NGOs. A "best" practice in our case should also have and the following features:

\subsection{Optimal utilization of resources}

The introduction of the society of knowledge, since the latter decades of the 20th century, illustrates the importance of human resources as the main productive factor of a modern economy requires a review of investment towards human capital. The development of human resources is now based on the establishment of an Economy of Knowledge Management, the main characteristic of which are the lifelong learning and the continuing training. The continuous renewal of knowledge, the continuous improvement of skills and human capital seems to constitute the necessary and sufficient condition of human development. Heart of this human development is the creation of conditions and terms of socio-economic and socio-cultural growth in all dimensions of the quality of life of modern human (Sarris et al, 2006). These developments could not leave unaffected the field of labor, which in conjunction with information and communication technologies, calls for reform of all standards and qualifications in the professional of employees (Sarris et al, 2006). Investing in human resources and production of additional skills become essential tools in terms of labor market and economy in a world where flexibility and quality are critical factors for the competitiveness of enterprises and national economies (see Papanaoum, 1996). The European Council in Lisbon in 2002 called for increased and improved investment in human capital. The optimal utilization of resources was one of the 13 specific objectives of the Program "Education and Training 2010" (European Council, 2002) and it was also included in the revised version of the Lisbon Strategy in 2005. The conclusions of the European Council in spring 2006 highlighted that "investing in education and training yield large profits which outweigh the costs and will have long term effects" (European Council, 2006). In March of 2008 European Council reaffirmed the need "for greater and more effective investment in human capital and creativity throughout life" as a prerequisite for the success of Europe in a globalized environment (European Council, 2008). Therefore, the objective of an employees' training should be the optimum utilization of human resources with a view to increasing efficiency.

\subsection{Needs assessment}

According to Miller and Osinski (2002) the detection and identification of training needs is a very important activity for the functions of training and development. It is the first step in creating effective training programs. Serves as the source for determining the learning objectives, designing training programs and assessment of training that eventually provided. (Cecada, 2010). According to Barbazette (2006) is the process of information gathering on a need that has either been reported or implied and which could be met by conducting training. Essential information gathered and analyzed in order to establish a proper training plan. The detection and identification of needs determine the need for training, identify what training is 
required and examines the type and nature of the resources needed to support the training program (Sorensen, 2002). According to McArdle (1998) the analysis of training needs often reveals the need for a highly specialized training. Through an effective needs assessment, is verified that training is the appropriate solution for a deficit in work performance. On the other hand, training, according to Sorensen (2002), can not solve problems caused by poor system design, inadequate resources or lack of staff. The detection and identification of needs helps to define the performance or knowledge level of the trainees before training and also helps to determine the level to be reached by the trainee. Those who carry out the needs assessment should be fully aware of issues are addressed and to consider all possible solutions before proposing to conduct training (Cecada, 2010). According to McArdle (1998) the needs assessment when performed correctly is a wise investment. Saves time, money and efforts while giving solutions to the right problems.

For needs assessment in the case of personnel of social partners and NGOs we should choose a complex methodological strategy to ensure the ideal condition of informational pluralism. In fact the method to be followed is the research triangulation (as suggested by Grounded Theory), which reinforces the heuristic nature of the needs assessment process. Under this method 3 data collection techniques are combined:

- Questionnaire (varied according to position of the trainee within the workplace)

- Group Intensive Interviewing with elements of focus groups

- Check Lists for the identification and prioritization of skills, abilities and needs.

By this method will be drawn both qualitative and quantitative data and will become easier to diagnose the needs of trainees while it will be easier to create modules for the training program and focus to its learning outcomes.

\subsection{Modularized training}

The modularizing describes the composition and the sequence of a program. It is used to give trainees more autonomy in setting up their own capabilities by combining training units and by adjusting the workload to their needs. In the more "extreme" forms of modularizing people can combine themes by following their own choices and setting their own "skills portfolio". Such models could be encountered in continuing education and training of Great Britain and Ireland. The mild model that can be encountered in the practical training of the Netherlands is characterized by final exams in various themes, as well as assessment and certification for each of the topics chosen by the students. This model aims to provide holistic and integrated approach to skills and make the system more flexible in terms of location and duration of learning. A function of learning outcomes is to provide greater flexibility and autonomy to training providers in determining the learning programs within the framework of a "rich" curriculum, creating thereby creating ideal conditions for approaches that focus on the trainee. Another important measure in order to focus on the vocational education and training to the trainee is the modularizing of training programs, which accompanies the introduction of learning outcomes in vocational education and training in many countries. The modularized training is a powerful tool to enable the vocational education and training to 
cope with trainee's needs, which have already been diagnosed through the needs assessment (CEDEFOP, 2010). The procedure of needs assessment includes approaches for the detection, identification, analysis and provision of new and changing skill needs of the trainees. Emphasis is given to the objectives, methods, classifications, data sources and valuation of skills for the agencies involved. This process is divided into two parts: a) the design of learning objectives and b) determining the expected learning outcomes. The learning outcomes are a function of knowledge, skills and abilities: LO (Learning Outcomes) $=\mathrm{K}$ (nowledge) $+\mathrm{S}$ (kills) $+\mathrm{C}$ (ompetences). The competences can be divided into generic competences and specific skills. The combination of a) and b) lead to the modularization of training curricula. The modularized training implies development of themes based on the skills and the appropriate learning materials (targeted training based on results of needs assessment). The modularized training in the case of training personnel of social institutions and NGOs is based on the following five elements:

1) Modular structure

2) Skill requirements derived from the workplace

3) Close cooperation with social partners, the structures of local communities and training experts

4) Personal curricula

5) Quality assurance of the acquired knowledge.

\subsection{Competences' assessment and learning outcomes}

The training in EU countries is directly related to the assessment and learning outcomes. According to the European Commission (2010) the capability assessment for specific target groups such as personnel of social institutions and NGOs may:

$>$ help learners to "learn to learn" and put the basis for lifelong learning

$>$ increase the informational pluralism

$>$ help trainees learn to acquire, assimilate and process new knowledge and skills and to increase their effectiveness in their workplace (European Commission, 2010b),

$>$ help learners to describe their true skills when looking for further opportunities in the workplace.

The evaluation should be used as a tool to clarify the learning outcomes and the future goals of training. The decisions on the assessment have a big impact on how the skills are being taught and therefore in how trainees learn. Minimum standards are now used in most of the countries for the assessment of knowledge acquired. Most important, however, the assessment capabilities in the design of training are the expected learning outcomes (learning outcomes). The learning outcomes are references to what it knows, understands and is able to make the learner after completion of the learning process and are defined as knowledge, abilities and skills (European Parliament \& Council of the EU, 2008). In this definition there 
is no separation of knowledge into formal, informal or non-formal. According to Adam (2006) learning outcomes are an assertion of what skills are expected to have a trainee as a result of the learning process. This statement can be interpreted in two ways: either the conditions of learning outcomes and skills mean the same thing by this definition the term a tautology or abilities describes specific aspects and connotations contained in the term learning outcomes and so is the clear meaning and utility (CEDEFOP, 2009).

According to Bulgarelli (2007) learning outcomes have become widely accepted and their influence is growing over European and national policies and practices. The learning outcomes introduce a common language among all the levels of education making it possible to compare and connect different levels and sectors of education, training and learning. On the one hand, the learning outcomes approach is able to capture all the richness and diversity of learning but on the other is a vulnerable method while its effectiveness relies heavily on its practical application.

Based on the international experience a social partners and NGOs personnel training, based on competency assessment and learning outcomes, must be based on the following main points:

- existence of specific indicators that demonstrate the starting point of human resources and development which has been or will be achieved through training,

- existence of specific timetables which will determine when the acquired from training skills will need upgrading or review

- sufficient documentation regarding to why such training is needed, what skills are expected to offer and whom concerns.

\subsection{Quality assurance}

Alongside, a practice to be considered "best" should be integrated into a crisp and efficient framework of quality assurance. The quality of a training program is a multidimensional and complex concept which refers to all its basic characteristics and therefore can not be a general and unambiguous definition. The quality of a training program determined by matching the specifications of the identified needs and the requirements intended to cover, while the quality of implementation is determined by the adequacy of an institution to implement a training program in accordance with predetermined specifications (Hasapis, 2000). According to CEDEFOP quality assurance in vocational education and training is a very important priority for promoting of transparency, mutual confidence, mobility and lifelong learning at European level (CEDEFOP, 2009). The European Union (after joint recommendation of the Parliament and the Council) in 2009 has created a European Framework for Quality Assurance in Vocational Education and Training (European Quality Assurance Reference Framework for VET). The Framework proposes a context of quality assurance and improvement. Specifically, that context includes: design, implementation, evaluation, review of corrections (European Commission, 2009). This framework gives new impetus to transparency and mobility, offering a common tool for the development of quality management practices (European Parliament \& Council, 2009). It is a 
new reference tool to assist the authorities of the Member States to promote and monitor the improvement of domestic systems of vocational education and training. Quality assurance can be used as a systematic approach to the modernization of education systems, notably by improving the effectiveness of training. Therefore, the quality assurance should be behind every policy initiative in vocational education and training (European Parliament \& Council, 2009).

\subsection{Certification and Evaluation}

The framework of quality assurance requires a clear framework for certification and evaluation in order to be completed. Nowadays certification in the form of a structured evaluation process of knowledge and skills required to pursue an occupation or perform a specific job guarantees the professional competence of the individual. Simultaneously, the certification to the extent that is integrated with a valid and reliable way to the training programs serves as a supporting agency to changes occurring in the content and structure of the workplace nowadays (National Centre for Public Administration and Local Government [EKKDA], 2008). The assessment of prior knowledge (informal, non-formal) is a major tool in the context of lifelong learning because it facilitates the participation in formal education and training, and also constitutes a means of enhancing the employability and mobility, the social participation and the active citizenship. The assessment of prior knowledge is a process of detection and measurement of capabilities of an individual, and whenever possible of their certification in the form of a (national) system of qualifications. The assessment of prior knowledge allows individuals to recognize and certify things that already know and can do. It is a process of discovery, documentation, evaluation and recognition of knowledge, skills and values acquired through formal and informal education and are related to specific criteria delineated by training centers, educational institutions or certification authorities. This process may include knowledge from work, experiences of life, training, independent study, volunteering, travel or family experiences. The recognition of prior knowledge can be used to meet the requirements for admission to an academic program or training or as a certification for professional qualification in order to have access to the labor market. It is important to highlight that competences framework provides the basis for certification of both prior knowledge and learning performance.

\section{Training personnel of social partners and NGOs}

To meet the complex needs of that specific target group, empirically acquired and very flexible training programs must be structured. The latter, as mentioned above, must be based on three pillars: needs-assessment - modularization - learning outcome-based. The harmonization in this triptych is based primarily on the correct diagnosis of needs. Emphasis is given to the objectives, the methods, the classifications, and to the valuation of skills. In order to extract measurable findings of the diagnostic needs is proposed, as noted above, the so-called methodological strategy of triangulation. To diagnose needs and develop new skills of the trainees, findings demonstrate the need for a systematic and functional combination of the horizontal knowledge and skills of the trainees with the development of special knowledge and skills through modules such as: 
- Development of negotiating skills and Decision Making

- Strategies for Conflict Management

- Basic Principles of Communication and influence in decision-making centers

- National, European and local context (knowledge of the existing framework and timely adaptation to new data)

- Development of cooperativeness among officials in the construction and production of proposals

- Creating and maintaining trade networks

- Analysis of Public Policies

In order to maximize the effect of the training, supporting supplementary modules are proposed, since there are serious deficiencies in both knowledge of procedures and relevant legislation, and in skills and knowledge required for the optimal utilization of new technologies.

Specifically, the supporting modules include:

$>$ Familiarization with the existing structures and procedures of trade union actions. Familiarization through upgrading the technological skills of trainees, with the modern direct forms of information and information dissemination technologies.

Familiarization with at least one foreign language in order to create and maintain a stronger, sustainable and efficient international network.

\section{Proposed framework of training program}

Each training program should be strictly focused with an emphasis on skills that have been selected to be developed. In particular, a detailed training program for the development of the negotiation capacity of the trainees will be as follows:

Table 1. Framework of training program

\section{Title of the program:}

Development of negotiating skills and Decision Making

\section{Characteristics of target group:}

The program is targeted at trade union representatives of the central and regional trade unions of the local government, and the Public Utilities, which have responsibility of negotiating with their departments. 


\section{Objectives of the program:}

The program aims to develop expertise and skills of participants in negotiating issues in order to be able to represent their colleagues, both in house and in interministerial meetings, and during the consultation meetings with non-statutory or external "players." After the program participants will be able to:

- Prepare a negotiation

- Develop the strategy and the objectives of a negotiation

- Apply methods of avoiding conflicts and finding solutions

- Identify critical factors affecting the negotiation and manage to take them into account in order to have a successful outcome.

\section{Modules of the program:}

1. Content and objectives of the training program

2. Hierarchy - Structure and Power

3. Decision making processes.

4. Principles of organizational behavior - culture. Modern competitive organizational systems.

5. Requirements of Negotiation. Typology of negotiators.

6. Management of changes and negotiation.

7. Preparation of Negotiation.

8. Characteristics of a good negotiator. The role of the negotiator.

9. Presentation of a good case of negotiation.

10. Principles, techniques, practices and negotiating tools.

11. Negotiation and mediation of conflicts.

12. Evaluation of Trainees.

\section{Evaluation of the training program:}

The evaluation of the program will take place as follows:

1. by completing a questionnaire both by trainees and trainers. This tool will include both closed and open questions with regard to all the components of the program.

2. by a group discussion of the Project Leader with the trainees at the end of the program on the achievement or not of the program objectives in order to identify strengths and weaknesses of the program, including proposals for improvement.

3. by a group discussion of the Project Leader with the trainers at the end of the program. 


\section{Macrothink}

\section{References}

Advance Africa. (2003). The Best Practices Compendium: Lessons learned from the Advisory Group, Final BPAG Meeting Report.

Barbazette, J. (2006). Training Needs Assessment: Methods, Tools and Techniques. London: Pfeiffer \& Co.

Cecada, T. (2010). Training Needs Assessment. Understanding what employees need to know, in Professional Safety, March 2010, pp. 28-33.

CEDEFOP (2009). Quality assurance in VET. Thessaloniki: CEDEFOP.

CEDEFOP. (2010). Learning outcomes approaches in VET curricula: A comparative analysis of nine European countries. Luxembourg: CEDEFOP.

Clarke, P.B., \& Foweraker, J. (2001). Encyclopedia of Democratic Thought. London and New York: Routledge.

Davidson, J. (2005). Theory-based needs assessment, in Canadian Evaluation Society \& American Evaluation Association conference. Retrieved from: $\mathrm{http}: / /$ realevaluation.com/tag/theory-based-needs-assessment/

European Commission. (2001). Making a European area of lifelong learning a reality. Brussels: DG EAC.

European Commission. (2009). EQARF: A tool for promoting better vocational education and training systems. Brussels: DG EAC.

European Commission. (2010). The European Qualifications Framework. Retrieved from http://ec.europa.eu/education/lifelong-learning-policy/doc44_en.htm

European Council. (2002). Detailed work programme on the follow-up of the objectives of Education and training systems in Europe. OJ 2002/C 142/01.

European Council. (2006). Key competences for lifelong learning, Recommendation of the European Parliament and of the Council of 18th December 2006, 2006/962/EC.

European Council. (2008). Presidency Conclusions, 13-14 March 2008.

European Parliament and Council. (2009). European Quality Assurance Reference Framework for VET, O.J. C 155, 8/7/2009.

Green, D. (2003). Guide to learning outcomes. Birmingham: University of Birmingham.

Hasapis, D. (2000). Design, organization, implementation and evaluation of vocational training programmes (in Greek), Athens: Metaixmio.

Kellaghan, T. et al. (2009). Using the results of a national assessment of educational achievement. Washington D.C.: The World Bank. 
Kieley, R. (1998). Neoliberalism revised? A critical account of World Bank conceptions of good governance and marked friendly interventions, in International Journal of Health Services, 28(4), 683-702. $\quad$ Retrieved from http://baywood.metapress.com/openurl.asp?genre=article \&eissn=1541-4469\&volume=2 $8 \&$ issue $=4 \&$ spage $=683$

Mayen, G. (2011). Social Partners in vocational education and training in the southern Mediterranean. Brussels: ETF.

McArdle, G. (1998). Conducting a need analysis. California: CrispLearning.

Miller, J., \& Osinski, D. (2002). Training Needs Assessment. London: SHRM.

Minerva, Working Group 6. (2003). First Selection of Good Practices and Competence Centers: State of the Art-Problems and Recommendations. Minerva Report.

Ministry of Education, Lifelong Learning and Religion. (2010). Towards a new Lifelong Learning Policy in Greece (in Greek). Athens: Ministry of Education, Lifelong Learning and Religion.

Ministry of Education, Lifelong Learning and Religion. (2010b). Draft Law "Development of Lifelong learning and other provisions" (in Greek), Athens: Ministry of Education, Lifelong Learning and Religion.

National Centre for Public Administration and Local Government. (2008). Training Certification System (in Greek). Athens: National Centre for Public Administration.

Papanaoum, Z. (1996). Continuing training in enterprises (in Greek), in the Proceedings of European Conference for the Quality Assessment Programs of Continuing Training, Larissa: Technological Educational Institute of Larissa.

Roy, K.C., \& Tisdell, C.A. (1998). Good governance in sustainable development: the impact of institutions, in International Journal of Social Economics, 25(6/7/8/), 1310-1325. http://dx.doi.org/ 10.1108/03068299810212775.

Sarris, M. et al (2006). Training needs assessment of social economic sector HR (in Greek). Athens: Technological Educational Institute of Athens.

Sorensen, S. (2002). Training for the long run: a cost benefit perspective. (Commissioning: Sound Investment), in Engineered Systems, Vol. 19, No.6. Retrieved from http://www.highbeam.com/doc/1G1-87078406.html

Special Service for Managing the "Digital Convergence Operational Programme" (2004). Annual Report 2004, Best Practices (in Greek). Retrieved from http://www.infosoc.gr

United Nations Population Fund (2004). Programme Manager's Planning Monitoring and Evaluation Toolkit. New York: UNFPA. 


\section{Copyright Disclaimer}

Copyright reserved by the author(s).

This article is an open-access article distributed under the terms and conditions of the Creative Commons Attribution license (http://creativecommons.org/licenses/by/3.0/). 